\title{
Exposure of hydrocarbon intumescent coatings to the UL1709 heating curve and furnace rheology: Effects of zinc borate on char properties
}

\author{
Zeng, Ying; Erik Weinell, Claus; Dam-Johansen, Kim; Ring, Louise ; Kiil, Søren
}

Published in:

Progress in Organic Coatings

Link to article, DOI:

10.1016/j.porgcoat.2019.06.020

Publication date:

2019

Document Version

Peer reviewed version

Link back to DTU Orbit

Citation (APA):

Zeng, Y., Erik Weinell, C., Dam-Johansen, K., Ring, L., \& Kiil, S. (2019). Exposure of hydrocarbon intumescent coatings to the UL1709 heating curve and furnace rheology: Effects of zinc borate on char properties. Progress in Organic Coatings, 135, 321-330. https://doi.org/10.1016/j.porgcoat.2019.06.020

\section{General rights}

Copyright and moral rights for the publications made accessible in the public portal are retained by the authors and/or other copyright owners and it is a condition of accessing publications that users recognise and abide by the legal requirements associated with these rights.

- Users may download and print one copy of any publication from the public portal for the purpose of private study or research.

- You may not further distribute the material or use it for any profit-making activity or commercial gain

- You may freely distribute the URL identifying the publication in the public portal 


\title{
Exposure of hydrocarbon intumescent coatings to the UL1709 heating curve and furnace rheology: Effects of zinc borate on char properties
}

\author{
Ying Zeng*, Claus Erik Weinell*, Kim Dam-Johansen*, Louise Ring ${ }^{\ddagger}$, Søren Kiil ${ }^{*}$ a \\ a: Corresponding author, email address: sk@kt.dtu.dk \\ *: Department of Chemical and Biochemical Engineering, Technical University of Denmark, DTU, Building 229, 2800 \\ Kgs. Lyngby, Denmark \\ †: Hempel A/S, Fire Protection-Group R\&D, Carretera de Sentmenat 108, 08213 Polinyà, Spain
}

\begin{abstract}
Hydrocarbon intumescent coatings are an efficient means to passive fire protection of steel structures in high-risk environments such as petrochemical plants and offshore platforms. In the present study, the effects of zinc borate on the performance of hydrocarbon intumescent coatings were investigated. The analyses include steel temperature-time relationships and char expansion, as well as structural investigations and compositional profiles of the char. Furthermore, transient rheological coating behaviors and thermal degradation of the coatings were measured and analyzed. Results of furnace experiments, conducted under a standard hydrocarbon fire curve (UL1709), showed that a formulation containing 15 wt.\% zinc borate gave the best performance. Fully expanded char measurements and the associated rheological recordings, evidenced that adjusting the zinc borate content from 0 to $20 \mathrm{wt}$ \% increased the dynamic viscosity minimum of the incipient char from 6.2 to $5671.4 \mathrm{~Pa} \cdot \mathrm{s}$. The increased dynamic viscosity resulted in a more uniform, but less expanded char layer. Compositional profiles of intumescent chars, measured using X-ray Diffraction, showed an increasing phosphate (especially $\mathrm{BPO}_{4}$ ) content with increasing levels of zinc borate in the intumescent coatings. Finally, the thermogravimetric analyses revealed that zinc borate can help to reduce epoxy binder degradation and oxidation of the carbon-inorganic residue. Due to the health risks associated with borate and its compounds, there is a requirement to find alternatives. The present work has mapped out some of the beneficial properties of zinc borate, and the results may provide some insight as to how to formulate without these compounds in the future.
\end{abstract}

Keywords: structural steel; fire-resistance performance; dynamic viscosity 


\section{Introduction}

Structural steel is a widely used construction material for multi-story buildings, process equipment, and off shore platforms. Though inherently non-combustible, the load bearing capability of steel decreases severely at elevated temperatures [1]; at a critical point of $500{ }^{\circ} \mathrm{C}$, approximately $50 \%$ of the original strength is lost [2-4]. When this happens, the structure may, due to the large mass involved, collapse. An efficient way to prolong the integrity of the structural steel in the event of a fire is to apply intumescent coatings to exposed surfaces. At elevated temperatures, these type of coatings will swell to a multicellular char layer that acts as a physical barrier, which will lower heat transfer rates and thereby prolong the time (1-3 hours) before the critical temperature of the substrate is reached $[5,6]$. The extended time to structure collapse will allow people longer escape time.

\subsection{Industrial fire testing of intumescent coatings}

Industrial fire testing of intumescent coatings employs standard fires with a preset temperature-time relationship. Depending on the source of "fuel", most of the standard fires are classified into two types: cellulosic fire (e.g. ISO 834) and hydrocarbon fire (e.g. UL 1709). Their corresponding intumescent coatings are called cellulosic intumescent coatings (mostly acrylic types with dry film thicknesses of $0.2-5 \mathrm{~mm}$ ) and hydrocarbon intumescent coatings (typically epoxy-based with dry film thickness of $2-40 \mathrm{~mm}$ ). The essential parameter of the industrial fire tests is the critical temperature at which the structural steel retains $60 \%$ of its original strength [5]. For regular loaded components, such as onshore platforms, $550{ }^{\circ} \mathrm{C}$ is generally selected as the standard critical temperature, while for heavily loaded components, such as offshore platforms, a temperature of $400{ }^{\circ} \mathrm{C}$ has been selected as the standard [5,7].

The chemistry involved in industrial fire tests of intumescent coatings is interactions between the so-called intumescent ingredients, i.e. acid source, char former, and blowing agent. A typical example is a system of ammonium polyphosphate (acid source), pentaerythritol (char former), and melamine (blowing agent) [8-10]. In the temperature range of 180 to $280{ }^{\circ} \mathrm{C}$, ammonium polyphosphate and its degradation products (orthophosphates, $\mathrm{PO}_{4}{ }^{3-}$, and phosphoric acid, $\left(\mathrm{HPO}_{3}\right)_{\mathrm{n}}$ ) react with hydroxyl groups of pentaerythritol through esterification, yielding an ester mixture [8]. At higher temperatures $\left(280\right.$ to $\left.350{ }^{\circ} \mathrm{C}\right)$, the esters are further converted into a carbonaceous mass via dehydration and carbonization. The low viscosity of the esters and the carbonaceous mass enable an expansion of the system by trapping gases released from decomposition of melamine and ammonium polyphosphate. Above $350{ }^{\circ} \mathrm{C}$, gelation and consolidation of the expanded mixture occur, giving rise to a multicellular char with a low thermal conductivity (e.g. for an epoxy-based 
coating below $\left.0.4 \mathrm{~W} \cdot \mathrm{m}^{-1} \cdot \mathrm{K}^{-1}[11]\right)$. At still higher temperatures, thermal degradation of the char (mainly oxidation of carbon) takes place.

\subsection{Objective and strategy of the present work}

This investigation deals with characterization of hydrocarbon intumescent coating chars formed according to the temperature-time curve of the UL 1709 standard, which has been widely adopted industrially for evaluating the effects of hydrocarbon-based fires in the petrochemical industry. Focus is on zinc borate, a functional filler (in this work specifically $2 \mathrm{ZnO} \cdot 3 \mathrm{~B}_{2} \mathrm{O}_{3} \cdot 3.5 \mathrm{H}_{2} \mathrm{O}$ ) well known in the coatings industry to have beneficial effects on the mechanical and thermal properties of intumescent coating chars. Zinc borate, for instance, can act as a flame retardant and in hydrated form it promotes the formation of a protective, cellular, and vitreous char layer. In addition, endothermic dehydration and evaporation of crystal water provide cooling effects [12]. Unfortunately, boron compounds also have some undesired effects on human health and reproduction [13], and the industry could face a ban on the use of these compounds in future years. Therefore, it is of interest to understand the mechanisms behind the positive effects of zinc borate to provide a scientific basis for the replacement of boron compounds.

The strategy of the investigation has been to evaluate the effects of zinc borate on the fire-resistance performance of selected coatings, when exposed to the fire curve UL 1709, and to characterize the chars being formed. Analyses techniques used for studying the process from virgin coatings, over melt states, to the formation of highly porous char layers are X-ray diffraction, rheology measurements, and flash-pyrolysis thermogravimetric analysis coupled with infrared spectroscopy.

\subsection{Previous investigations on intumescent coatings containing functional fillers}

The investigation of this work is concerned with hydrocarbon intumescent coatings and the use of zinc borate as a functional filler. Consequently, it would be relevant to focus on a discussion of past work on these coatings. However, quite often, the type of intumescent coating (cellulosic or hydrocarbon) used in an analysis is not stated directly [6,14-21]. Only in a limited number of papers (e.g. [22,23], where the effects of organoclay and expandable graphite were investigated in silicone-based binders) is it explicitly stated, that a standard hydrocarbon fire curve was followed. Therefore, this short review will include studies with a focus on the importance of filler materials, irrespective of the type of intumescent coating employed. However, it must be emphasized, that the use of a standard or standard-like fire curve can be rather critical, especially when it comes to hydrocarbon intumescent coatings. The high heating rate (more than $200 \mathrm{~K} / \mathrm{min}$ ) and dwelling temperature (in excess of $1100^{\circ} \mathrm{C}$ ) required for hydrocarbon fire curves are difficult to fulfill with regular laboratory equipment, such as Bunsen burners, gas lamps, or cone calorimeters, even though 
these devices are the most common alternatives for the investigation of intumescent coatings $[9,24,25]$. The concern is that the fire-resistance performance and the intumescent char obtained with a setup of low or uncontrollable heating rate could be dramatically changed under the severe heating conditions of a hydrocarbon fire curve [22,26,27].

Ullah and his coworkers studied the effect of fillers (e.g. kaolin, boric acid, basalt fiber, and zirconium silicate) on the thermal performance of intumescent coatings with the aid of a Bunsen burner and a Carbolite furnace (heating rate of 10-20 K/min) [14-18,25]. Wang et al., on the other hand, constructed a Gaslamp to evaluate the influence of epoxy binder, glass flakes, montmorillonite, and silicone emulsion, respectively, on fire protection of waterborne intumescent coatings [21,28-30]. Yew et al. investigated interactions between flame-retardant fillers (eggshell, $\mathrm{Mg}(\mathrm{OH})_{2}$, and $\left.\mathrm{Al}(\mathrm{OH})_{3}\right)$ and an intumescent coating system (ammonium polyphosphate/pentaerythritol/melamine) with a Bunsen burner [6,20]. Using thermogravimetric analyses, X-ray diffraction, and scanning electron microscopy, these investigations proved that thermal stability and char structure could be improved by adjusting the level of target filler in the intumescent formulations. For the cases of phosphate derivatives (e.g. ammonium polyphosphate) as the acid source, a probable reaction is that fillers can yield phosphates, such as zinc phosphate and boron phosphate, by consuming the acid source [8,19,31,32]. Often, these phosphates are assumed to reinforce the structure of the intumescent chars, although, due to insufficient investigations (particularly, the rheological aspect of a hydrocarbon intumescent coating), the mechanism behind the reinforcement is not fully understood. Gillani et al. [12] experimented with nano-sized zinc borate as a substitution of boric acid for thermal degradation and gaseous products in expandable graphite-based intumescent coating systems. The heating source used was a Bunsen burner. They found that nano-size zinc borate promotes more continuous and compact char layers, less toxic gases, and that a zinc-based glassy intumescent "shield" can form that strengthens the char. It was not stated if the coating used was a hydrocarbon or cellulosic type (an epoxy binder was used, but the fire test applied, ASTM E-119, is for cellulosic coatings).

In summary, functional fillers can have a strong influence on the char formation and properties. Comprehensive investigations on the physical (e.g. char expansion and strength and rheological behavior) and chemical (e.g. thermal reactivity and anti-oxidation) properties are essential to understand the intumescent mechanisms of a hydrocarbon intumescent coating formulated with functional fillers. 


\section{Experimental}

2.1. Coating materials and application

An intumescent coating with different contents of zinc borate was formulated with a twocomponent (base and curing part) epoxy system. The base part was composed of a bisphenol A epoxy resin (Hexion B.V.), a diluent (ICL-IP B.V.), and several fillers: ammonium polyphosphate (Clariant $\mathrm{GmbH}$ ), zinc borate (Borax Ltd.), calcium carbonate (Reverté Minerales S.A.), and silicate fibers (Rockwool B.V.). For the zinc borate powder used, the maximum-, minimum-, and mean volume-based (D [4;3]) diameter was measured to respectively, 22.40, 0.40, and $9.62 \mu \mathrm{m}$. The curing agent was a mixture of an amide and a catalyst from Air Products B.V., formulated with melamine (OCI Nitrogen B.V.) and titanium dioxide (Huntsman Ltd.). The carbon source of the coating was the epoxy binder itself (no additional carbon source was added). The composition of the intumescent coatings used and the name assigned to the various formulations are listed in Table 1. To adjust the level of zinc borate, the binder content was varied accordingly. The influence introduced by the change in binder content (e.g. char expansion and thermal degradation of coating) will be taken into account later when discussing the effects of zinc borate. A high-speed disperser (800 rpm, $300 \mathrm{rpm}$ after addition of fibers) was used for mixing (and dispersion) of the various ingredients. The temperature of the mixture was kept below $50{ }^{\circ} \mathrm{C}$ during dispersing.

Table 1 Composition of the series of intumescent coatings (in wt. $\%$ ), APP = ammonium polyphosphate, MEL = melamine.

\begin{tabular}{lccccccc}
\hline Name & APP & MEL & $\mathrm{CaCO}_{3}$ & Fiber & $\mathrm{TiO}_{2}$ & $\begin{array}{c}\text { Zinc } \\
\text { borate }\end{array}$ & $\begin{array}{c}\text { Epoxy } \\
\text { binder }^{\mathrm{a}}\end{array}$ \\
\hline ZB0 & 15.79 & 12.63 & 1.44 & 10.18 & 3.44 & 0.00 & 56.52 \\
ZB5 & 15.79 & 12.63 & 1.44 & 10.18 & 3.44 & 5.00 & 51.52 \\
ZB10 & 15.79 & 12.63 & 1.44 & 10.18 & 3.44 & 10.00 & 46.52 \\
ZB15 & 15.79 & 12.63 & 1.44 & 10.18 & 3.44 & 15.00 & 41.52 \\
ZB20 & 15.79 & 12.63 & 1.44 & 10.18 & 3.44 & 20.00 & 36.52 \\
\hline
\end{tabular}

${ }^{a}$ Total amount of epoxy resin, diluent, amide, and catalyst.

Application of intumescent coatings was initiated by mixing two parts (base and curing agent) according to a specific amide/epoxy stoichiometric ratio of 0.867 . For the furnace experiments, a coating thickness of $6 \pm 0.2 \mathrm{~mm}$ was applied to the surface of a grit-blasted steel plate (area of 60x60 $\mathrm{mm}^{2}$ and $3 \mathrm{~mm}$ thickness) using first a spatula and then a roller. No mesh was used to reinforce the coating. A circular PVC frame (diameter of $25 \mathrm{~mm}$ and $2 \mathrm{~mm}$ height) or a petri dish 
was used to cast free liquid films of the coating for rheological measurements and thermogravimetric analysis, respectively. All samples were cured for $24 \mathrm{~h}$ at room temperature before use.

\subsection{Furnace experiments with standard hydrocarbon fire curve}

Furnace experiments were carried out with an oven (LHT 01/17D from Nabertherm GmbH) that can simulate the temperature-time curve defined by the standard hydrocarbon fire test UL1709. In Figure 1a, the dashed lines are the experimental UL1709 curves mimicked by the laboratory oven, which show few differences compared with the standard UL1709 curve (solid black line). The coated steel plate, held in place with a tailor-made insulating cap (Figure 1b), was put inside the oven chamber during the furnace experiment. Ventilation of the chamber was controlled (on a scale from fully open to closed) by adjusting a fresh air lever, placed at the front panel of the oven. To qualitatively simulate the rather low oxygen concentration in the local gaseous environment of an industrial furnace, the lever was adjusted to an intermediate position.

A thermocouple (type $\mathrm{K},-50-1200{ }^{\circ} \mathrm{C}$ ) was attached to the backside of the steel plate to record its temperature versus time response. To make sure that the temperature response of the steel plate results from heat transfer through the intumescent coating only, the sides and the backside of the steel plate were insulated with cap and oven insulation material, respectively. Once the temperature of the steel plate reached $550{ }^{\circ} \mathrm{C}$, the oven was turned off. Repeatability was assessed using a 3-fold repetition of the furnace experiments with a model intumescent coating. Results are shown in Figure 1a. It can be seen that the temperature-time repetition curves for the coating overlap. The standard deviations of the time to reach the critical temperatures $\left(400\right.$ and $\left.550{ }^{\circ} \mathrm{C}\right)$ are less than $1 \%$. Given the good repeatability, the furnace experiments with the five target formulations were only performed twice, unless a considerable deviation was found, in which case at least three repetitions were conducted. 
(a)

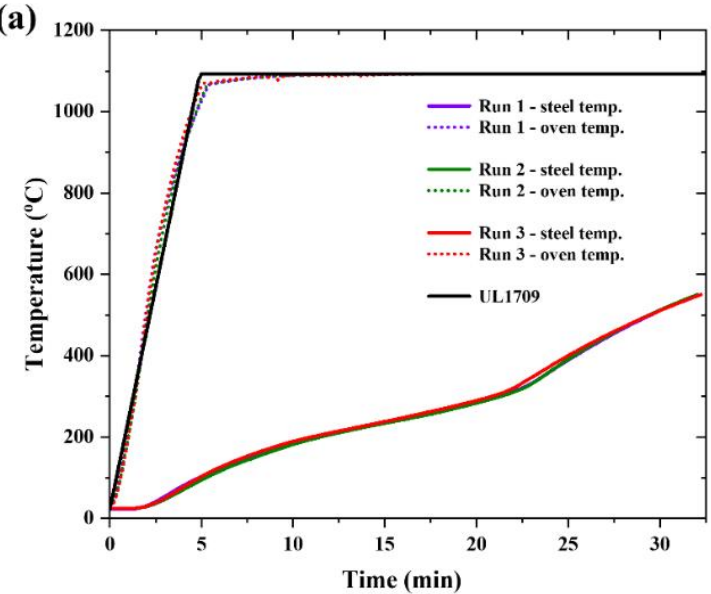

(b)

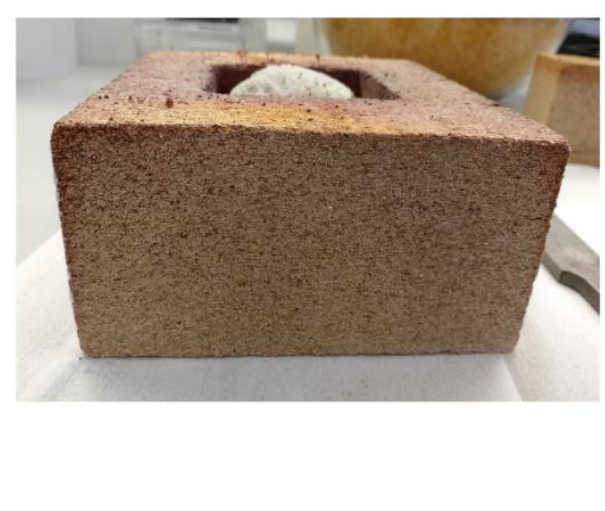

Figure 1 (a) Transient measurements of steel substrate temperatures during three repetitive furnace experiments with an intumescent coating (b) an insulating cap for support of intumescent coatings during experimentation (the grey part, barely visible in the middle is the top of an intumescent coating char after an experiment).

\subsection{Scanning electron microscopy and digital microscopy recordings of the char structure}

The morphology of char structures was analyzed with a scanning electron microscope (Inspect S, from FEI) operated at an accelerating voltage of $20 \mathrm{kV}$ and a digital microscope (VHX-6000, from KEYENCE) with the lens VH-Z20T, which can magnify up to 200 times.

\subsection{Rheological measurements of the incipient intumescent char}

The dynamic viscosity (also termed the complex viscosity) of a viscoelastic material as a function of temperature was measured on a rheometer DHR-2 (TA Instruments) with a disposable parallelplate configuration. The free circular films of intumescent coating (Ø25 mm x $2 \mathrm{~mm}$ height) were placed between the plates and an oscillation temperature ramp with a heating rate of $50{ }^{\circ} \mathrm{C} / \mathrm{min}$, a displacement of $5 \cdot 10^{-5} \mathrm{rad}\left(5 \cdot 10^{-5} \mathrm{rad}\right.$ for low viscous phases), and a frequency of $5 \mathrm{~Hz}$ was applied for measurements from 30 to $600{ }^{\circ} \mathrm{C}$. A low axial force adjustment $(0 \pm 0.1 \mathrm{~N})$ was activated so that the gap between the plates was continuously adjusted to accommodate the intumescence (expansion) during heating.

\subsection{Crystalline phases of the intumescent char identified with X-ray diffraction}

The Crystalline phases of the intumescent coating chars, produced in the furnace experiments, were identified on a Huber G670 powder diffractometer with CuK(alpha)1 radiation $(\lambda=1.54058 \AA$, $40 \mathrm{keV}, 40 \mathrm{~mA}$ ) using a focusing primary monochromator, in transmission mode in the range 3 to 100 degrees in 2(theta) for 30 minutes. 


\subsection{Thermal reactivity of formulations}

Thermogravimetric analyses of the hydrocarbon intumescent coatings were performed at 213 ${ }^{\circ} \mathrm{C} / \mathrm{min}$ in a flow of $\mathrm{N}_{2}\left(79 \mathrm{~mL} / \mathrm{min}\right.$, purity grade 5) and $\mathrm{O}_{2}(21 \mathrm{~mL} / \mathrm{min}$, purity grade 5$)$, using a Netzsch Jupiter F1 STA coupled with a Fourier transform infrared spectroscopy (FTIR). The powdery samples (approximately $45 \mathrm{mg}$ ), ground from the free films of the intumescent coatings, were put in alumina crucibles and heated from room temperature to $1000{ }^{\circ} \mathrm{C}$. Gases released during heating were transported to the FTIR chamber and detected according to the absorption of the FTIR beam $\left(650-4200 \mathrm{~cm}^{-1}\right)$. The temperature of the absorption chamber was kept at $200{ }^{\circ} \mathrm{C}$.

To assess the interactions between zinc borate and other ingredients in the formulations, the "theoretical' residual weight ( $\mathrm{W}_{\text {theo, }}$, in the unit of wt.\%) after exposure at the specific heating rate $\left(213{ }^{\circ} \mathrm{C} / \mathrm{min}\right)$ was calculated using equation (1).

$$
\mathrm{W}_{\text {theo }}(\mathrm{T})=\mathrm{W}_{\mathrm{ZB} 0}(\mathrm{~T})+\mathrm{x}_{\mathrm{ZB}}\left[\mathrm{W}_{\mathrm{ZB}}(\mathrm{T})-\mathrm{W}_{\mathrm{EB}}(\mathrm{T})\right]
$$

Here, $\mathrm{W}_{\mathrm{i}}$ is the residual weight of substance $\mathrm{i}$ (unit is wt.\%), $\mathrm{i}=\mathrm{ZB} 0$ (coating ZB0), $\mathrm{ZB}$ (pure zinc borate), or EB (pure epoxy binder); $\mathrm{XZB}_{\mathrm{ZB}}$ is the weight fraction of zinc borate in the target coating. The second term on the right-hand side of eq (1) accounts for zinc borate replacement of binder in the formulations containing zinc borate.

The theoretical residual weight represents the case when zinc borate does not interact with other coating ingredients. $\mathrm{W}_{\mathrm{ZB}}$ and $\mathrm{W}_{\mathrm{EB}}$ can be read from separate mass loss curves of pure zinc borate and pure epoxy binder. Considering the possible interactions between the epoxy binder and other ingredients in the formulation ZB0, two boundary conditions (maximum and minimum decomposition of the epoxy binder in ZB0) were calculated and used as the deviation from the theoretical residual weight.

\section{Results and discussion}

3.1. Effects of zinc borate on the performance of hydrocarbon intumescent formulations

\subsubsection{Fire-resistance performance}

The temperature versus time curves obtained from the furnace experiments are shown in Figure $2 \mathrm{a}$. For the sake of clarity, results from duplicated experiments are not provided (repeatability of the curves is excellent, as shown in Figure 1a). Exposure times to reach critical temperatures (400 and $550{ }^{\circ} \mathrm{C}$ ) are provided in Figure $2 \mathrm{~b}$. The critical times are averages ( \pm standard deviation) of the repetitive furnace experiments. 

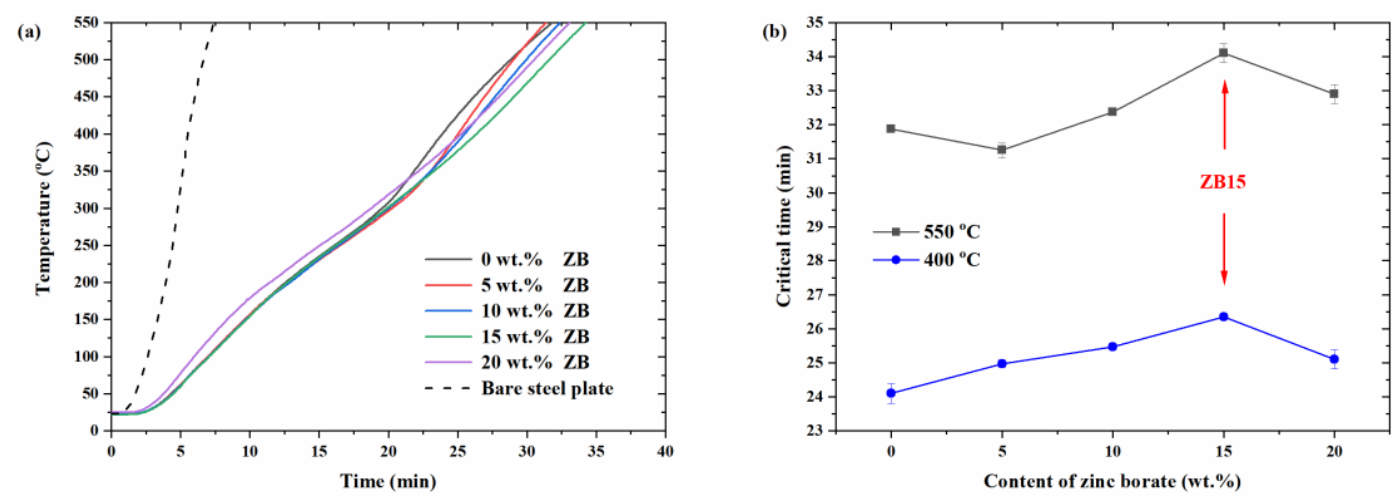

Figure 2 (a) Temperature versus time curves for the intumescent coatings ( $\mathrm{ZB}=$ zinc borate). The response of the uncoated steel plate is included for comparison. (b) Average exposure times to reach critical temperature of steel substrate (based on repeated furnace experiments). Error bars correspond to the standard deviation.

The bare steel plate reaches its critical temperature within only 7.5 minutes. When intumescent coatings were applied, this time was observed to exceed 30 minutes $\left(550{ }^{\circ} \mathrm{C}\right)$. All coatings showed almost the same temperature-time response from 0 to $20 \mathrm{mins}$, except for the formulation with a very high concentration of zinc borate (20 wt.\%, ZB20). Thereafter, the curves diverged leading to differences in critical times. The critical times presented in Figure $2 \mathrm{~b}$ represent the fire-resistance performance of the coatings. The best performing formulation is ZB15 (15 wt.\% zinc borate), which has the longest critical time for both 400 and $550{ }^{\circ} \mathrm{C}$, while the worst performance changed from ZB0 to ZB5 when the critical temperature increased from 400 to $550{ }^{\circ} \mathrm{C}$. The trends in Figure $2 \mathrm{~b}$ clearly demonstrate that zinc borate can improve the fire-resistance performance of hydrocarbon intumescent coatings, even though the absolute difference between the critical times of the formulations is surprisingly small.

The degree of expansion of the intumescent chars was estimated by averaging the height measurements of the (cooled) chars produced from the repetitive furnace experiments. The results are plotted in Figure 3, which shows that the expansion of the chars is dramatically constrained with zinc borate in the formulation. According to the work of Canosa et al. [33], the level of expansion is directly proportional to the pigment volume concentration, or, equivalently, the binder content. However, the disproportional change seen in Figure 3 points to a more active role of zinc borate in limiting the char expansion because the level of zinc borate was adjusted in the formulations by a proportional reduction of the binder content. 


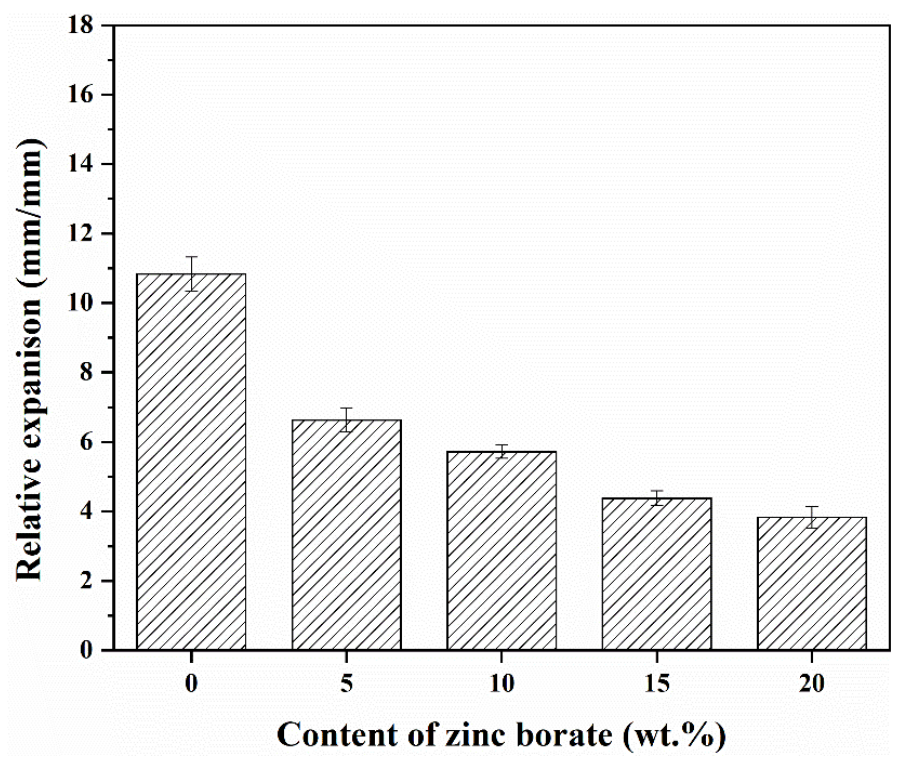

Figure 3 Coating char expansions (measured at room temperature) relative to the initial coating thickness as a function of zinc borate in the coatings. Error bars represent the standard deviation.

It can be seen, from a comparison of Figure 2 and Figure 3, that the higher expanded chars did not bring a better fire-resistance protection of the substrate. The reason for this is that the chars with high expansions may suffer from an inferior internal structure. For instance, a soft and fragile char with defects (e.g. delamination) can compromise the thermal heat conductivity [34]. .

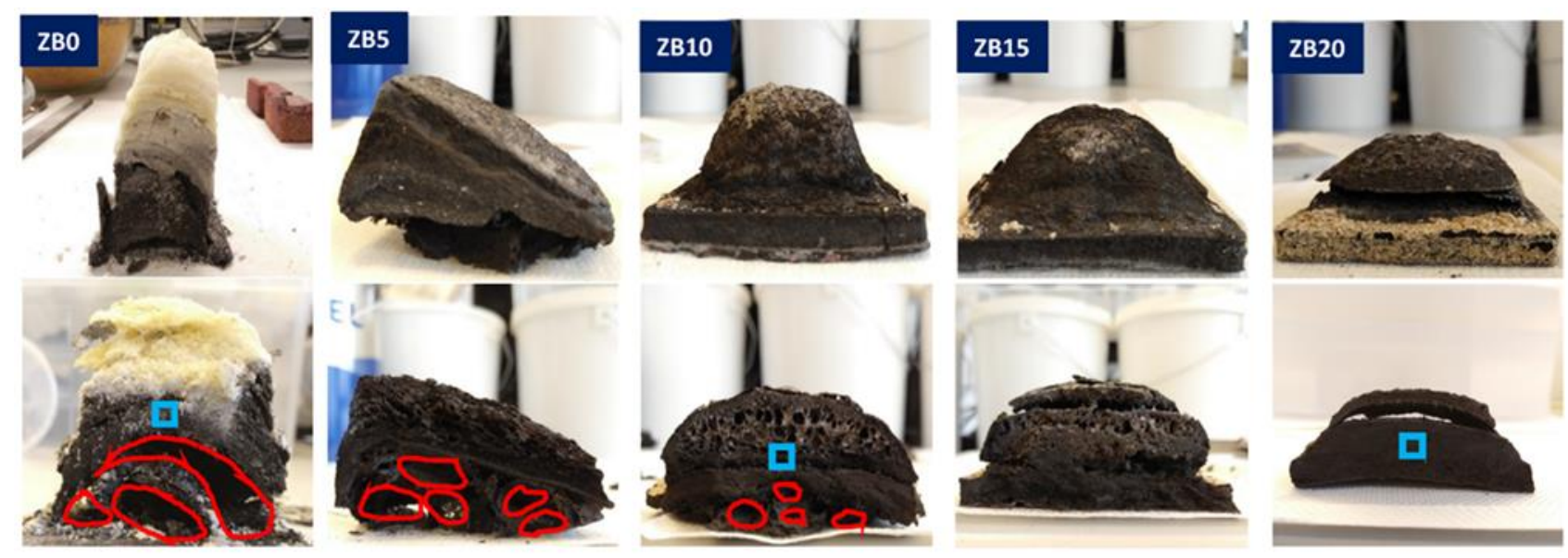

Figure 4 and 5 show the physical appearance and inner structure of the fully expanded intumescent coating chars. 


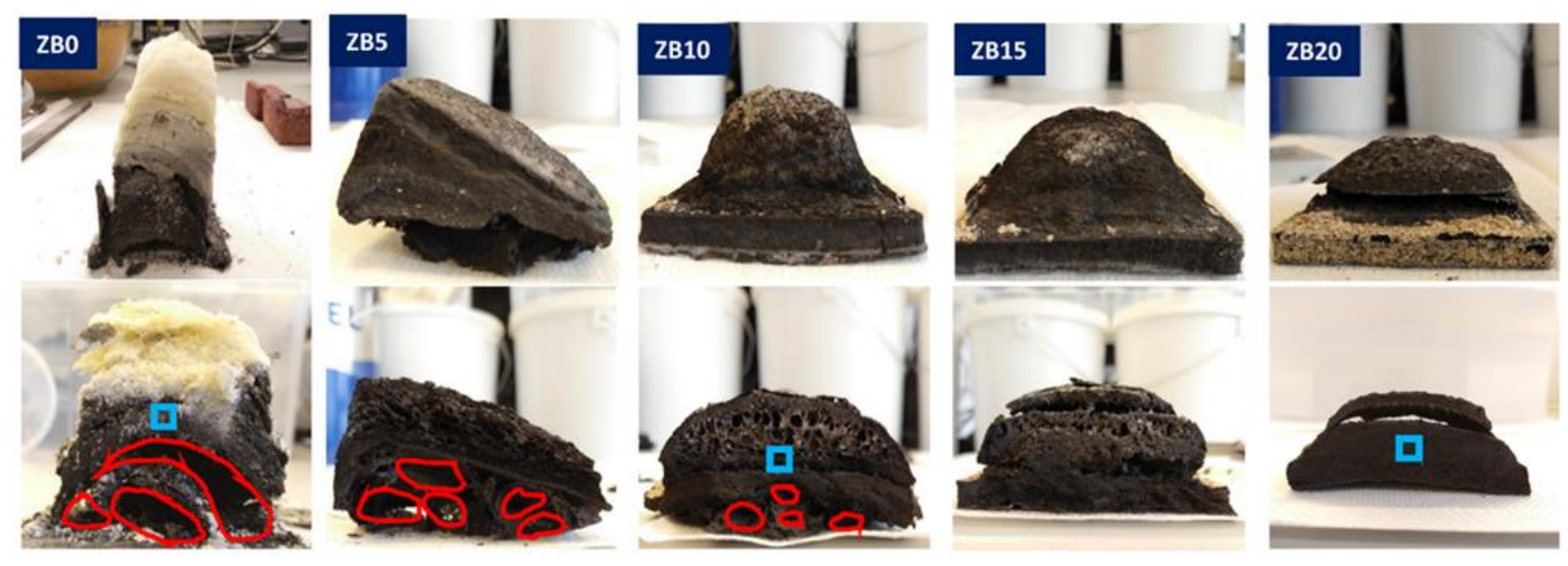

Figure 4 Top line: intumescent coatings (in the form of char) after furnace experiments; Bottom line: corresponding cross-sections of the chars (after use of a scalpel) with the big voids (width $>5 \mathrm{~mm}$ ) highlighted in red. The blue squares indicate the approximate positions where the corresponding SEM images (shown in Figure 5) were recorded. 
(a)
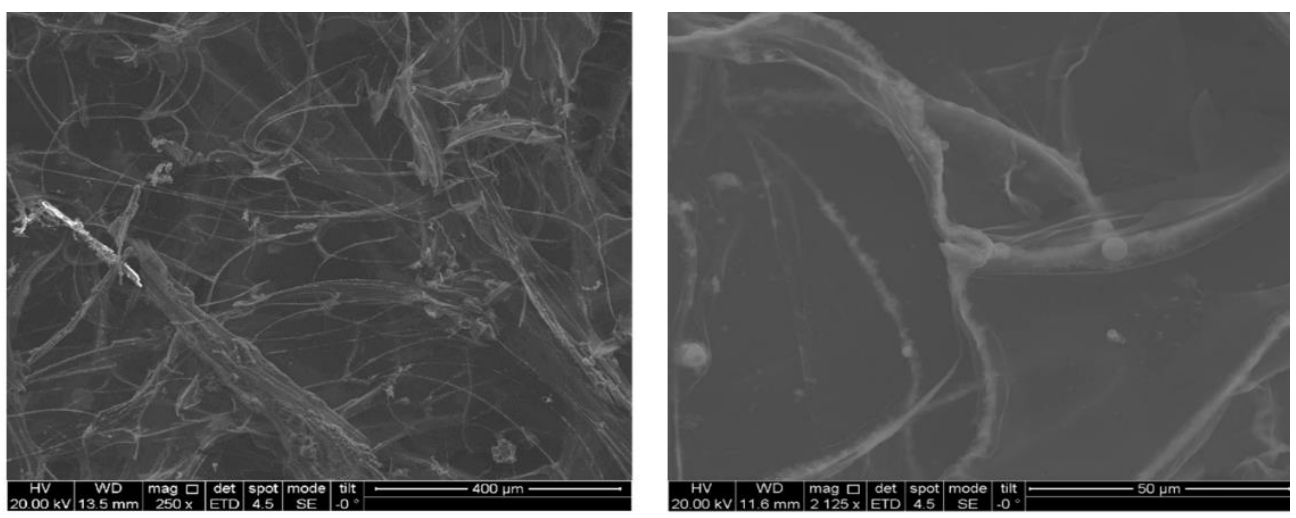

(b)
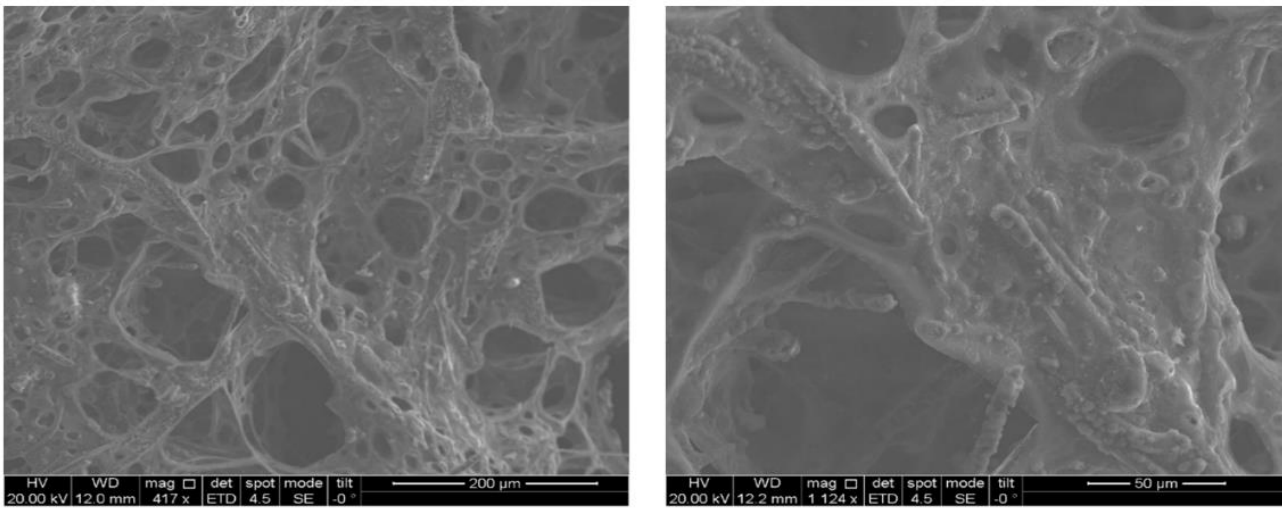

(c)
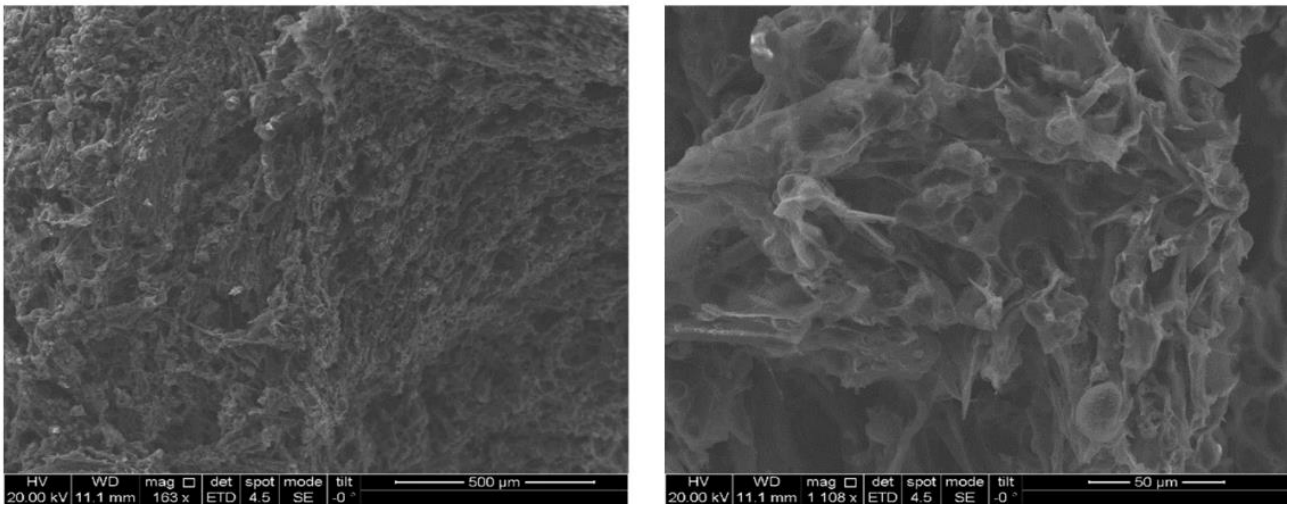

Figure 5 SEM images of the inner char structures: (a) ZB0, (b) ZB10, and (c) ZB20. Note that the magnifications in the left-hand images are not the same.

The fluffy char with a thin-film structure seen for formulation ZB0, cannot provide sufficient protection, regardless of this char having the highest degree of expansion. This undesirable structure is improved with zinc borate in the coatings. Specifically, zinc borate results in more uniform chars with less and smaller voids (cells) as seen in . 


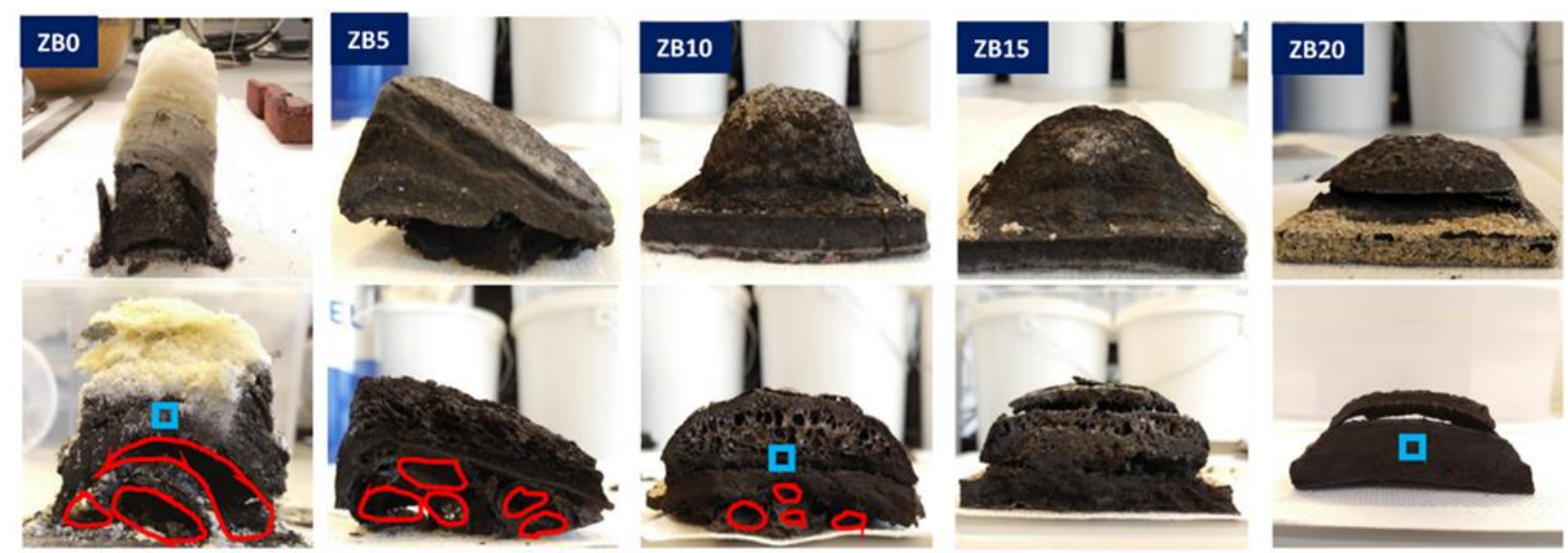

Figure 4 and 5. Overall, with increasing levels of zinc borate, the images in Figure 5 show a transition from filaments, to a foam-like structure, to a dense phase. The dense structure is optimal with respect to insulation properties of the char. The char ZB0 has a distinct light-yellow layer in the top structure, which is a typical result of oxidation of the intumescent char. It suggests that zinc borate may also play a role in reducing char oxidation. This observation is further discussed in the section on thermogravimetric analyses.

In spite of the benefits, a high level of zinc borate in the hydrocarbon intumescent formulation can introduce delamination and cracks in the char structure. The former was found in the case of ZB15 and ZB20 (top part of the shell in .
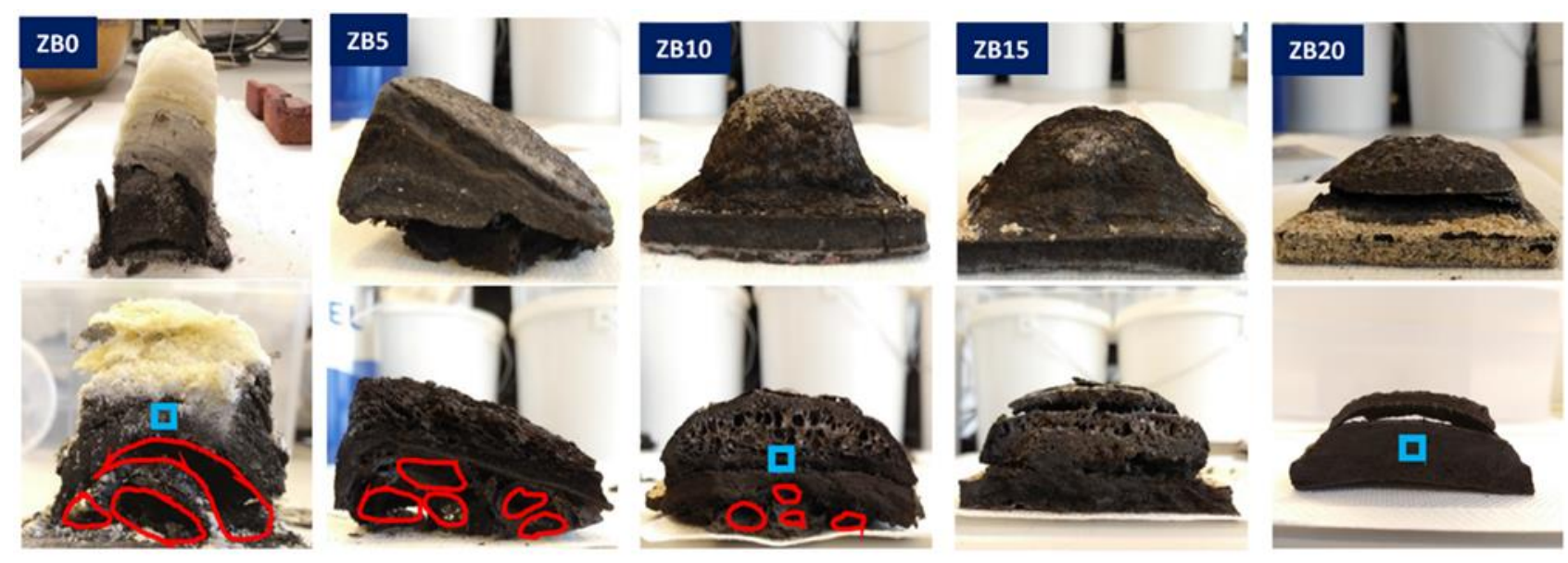

Figure 4). The partly detached upper part of char ZB15 was connected with the rest of the char structure after the furnace experiments, its damaged structure only became visible when the char was cross-sectioned. The char ZB20, on the other hand, presents a delaminated shell that is completely detached from the rest of the char. Moreover, the char ZB20 shows cracks on the surface below the detached shell.

The positive (e.g. homogenizing the char structure) and negative (e.g. limited char expansion and introducing cracks) effects of increasing zinc borate content in the hydrocarbon intumescent 
coatings may be the cause of the threshold value (15 wt.\% zinc borate) of the fire-resistance performance presented in Figure 2.

\subsubsection{Viscoelastic behavior of incipient chars}

Structure and apparent expansion of chars are closely related to rheological properties of the intumescent coatings. Figure $6 a$ shows the dynamic viscosity of the intumescent coatings as a function of temperature.

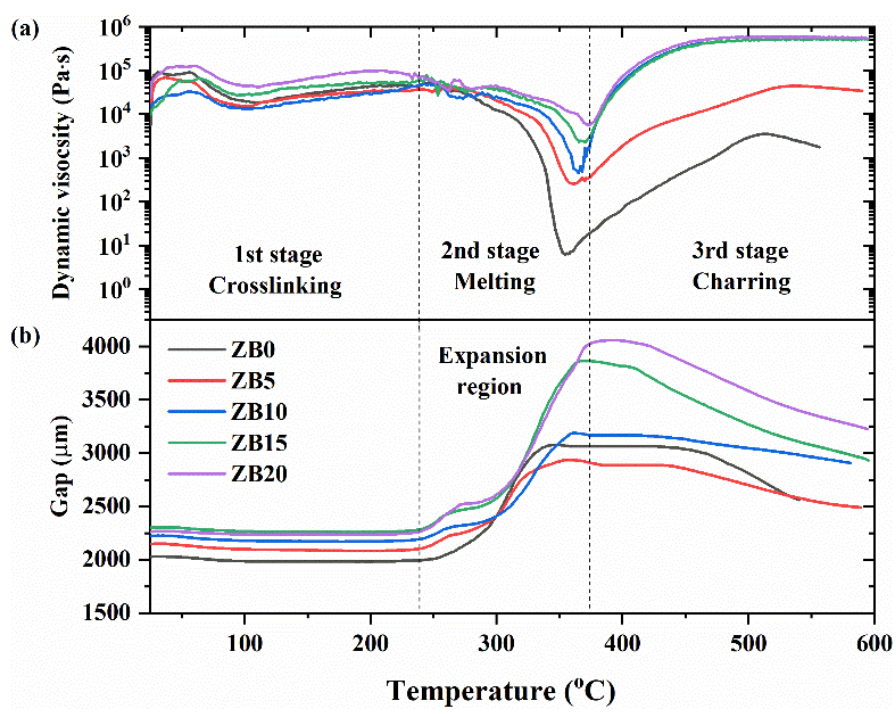

Figure 6 Dynamic viscosity (a) and gap change (b) caused by the expansion of the incipient chars for the intumescent coatings measured with a rheometer.

All formulations show a similar dynamic viscosity change that can be roughly divided into three stages. The first stage lasts until a temperature of around $235{ }^{\circ} \mathrm{C}$, characterized by a small peak in the dynamic viscosity before $100{ }^{\circ} \mathrm{C}$ and a subsequent moderate growth. The dynamic viscosity change during this stage mainly results from the temperature dependence and crosslinking reactions of the thermoset epoxy [35]. The second stage refers to the dynamic viscosity drop during the temperature change from 235 to $375{ }^{\circ} \mathrm{C}$, taking the coating to a dynamic viscosity minimum. The subsequent rise in dynamic viscosity pushes the coating into the third stage.

In summary, the three stages correspond to crosslinking, melting (viscoelastic substance), and charring. Figure $6 \mathrm{~b}$ shows the gap change of the parallel-plate configuration during the dynamic viscosity measurement. Owing to the axial force adjustment of the rheometer, the gap varies with the expansion of the intumescent coating. The obvious increase of the gap (i.e. the expansion of the coating) was observed during the temperature range of 235 to $375^{\circ} \mathrm{C}$ for all the formulations, which 
matches the temperature range for the second stage in Figure 6a. This result supports the conclusion reported by Jimenez et al. [34]; that a positive correlation exists between the dynamic viscosity of the viscoelastic material (i.e. the second stage) and the expansion of hydrocarbon intumescent coatings.

In Figure 6a, the second stage shows that the extent of dynamic viscosity drop was reduced with increasing levels of zinc borate in the formulations. The changes in the dynamic viscosity of the viscoelastic substance coincide with the results of the char expansion discussed in section 3.1.1. The highest expansion after the furnace experiment was obtained with the formulation ZB0, which formed the viscoelastic substance with the lowest dynamic viscosity minimum $(6.2 \mathrm{~Pa} \cdot \mathrm{s})$ at the end of the second stage. The highest dynamic viscosity minimum (5671.4 $\mathrm{Pa} \cdot \mathrm{s}$ ) is in the case with the highest amount of zinc borate (ZB20), which corresponds to the lowest char expansion after the furnace experiments.

The mechanism behind the correlation of the dynamic viscosity minimum and the char expansion can be explained by the diffusion of the gases in the incipient char. To get an appropriate multicellular char, the gases released from the intumescent ingredients (mainly blowing agent) need to be trapped and subsequently diffuse slowly in the viscoelastic material [34]. For the coating without zinc borate (ZB0), the dynamic viscosity during this stage is too low to ensure proper entrapment of gases in the matrix and a high expansion with large voids is expected. If the dynamic viscosity is increased by enhancing the amount of zinc borate in the formulation, the viscoelastic material is able to accommodate the pressure from the evolving gas, and to create a more uniform and firm char. However, if the dynamic viscosity is too high, the viscoelastic mass will slow down gas evolution and limit diffusion, leading to a rigid and thin layer with a high level of internal stress. In this case, cracks easily form and propagate [34], which explains the inferior structure (cracks and delamination) in the char ZB20.

\subsubsection{Chemical composition profiles of intumescent chars}

The chemical composition of the intumescent chars produced from the furnace experiments was analyzed with depth profiles using X-ray diffraction (XRD). To enable this, the chars were divided into three zones, based on color and structure, as shown in Figure 7 for the cross-section of ZB15. 


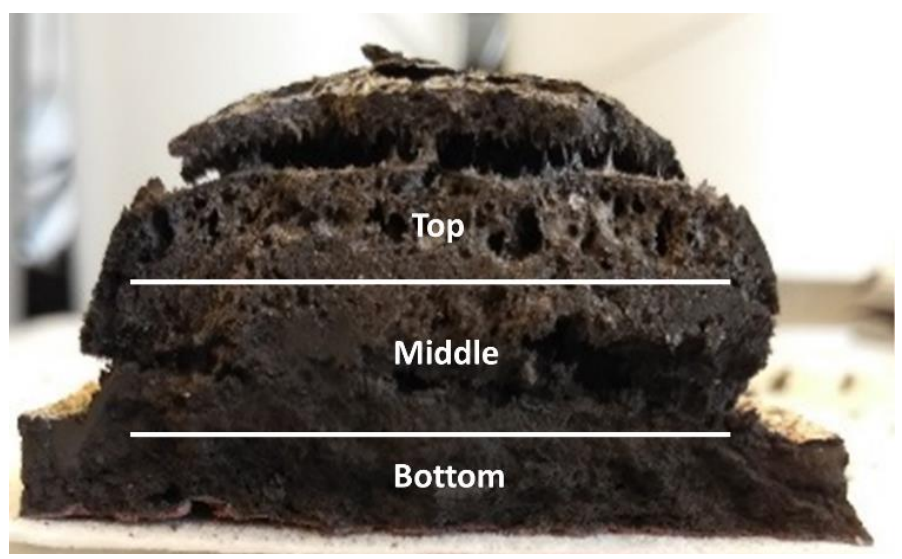

Figure 7 Cross-section view of three-layer structure in intumescent coating char (ZB15 from the furnace experiment as an example).

The crystal phases identified in each layer of the chars are presented in Figure 8. For ZB0, the main characteristic peaks are $\mathrm{AlPO}_{4}$ and $\mathrm{Ti}_{4} \mathrm{P}_{6} \mathrm{O}_{23}$ (top and middle and top) and $\mathrm{TiO}_{2}$ (bottom). For the formulations with zinc borate, on the other hand, the main crystal phases identified in the layers change from $\mathrm{Ti}_{4} \mathrm{P}_{6} \mathrm{O}_{23}$ (top), to $\mathrm{BPO}_{4}$ and $\mathrm{Ti}_{4} \mathrm{P}_{6} \mathrm{O}_{23}$ (middle), and to $\mathrm{TiO}_{2}$ and $\mathrm{BPO}_{4}$ (bottom). The composition change from top to bottom layers is probably related to the temperature gradient inside the char during the furnace experiment. The higher temperatures of the top layers increase reaction rates and allow an earlier conversion of reactants into products, thereby resulting in peak diminishment (e.g. $\mathrm{TiO}_{2}$ and $\mathrm{BPO}_{4}$ ) and peak growth (e.g. $\mathrm{Ti}_{4} \mathrm{P}_{6} \mathrm{O}_{23}$ and $\mathrm{AlPO}_{4}$ ). 
(a) Top layers

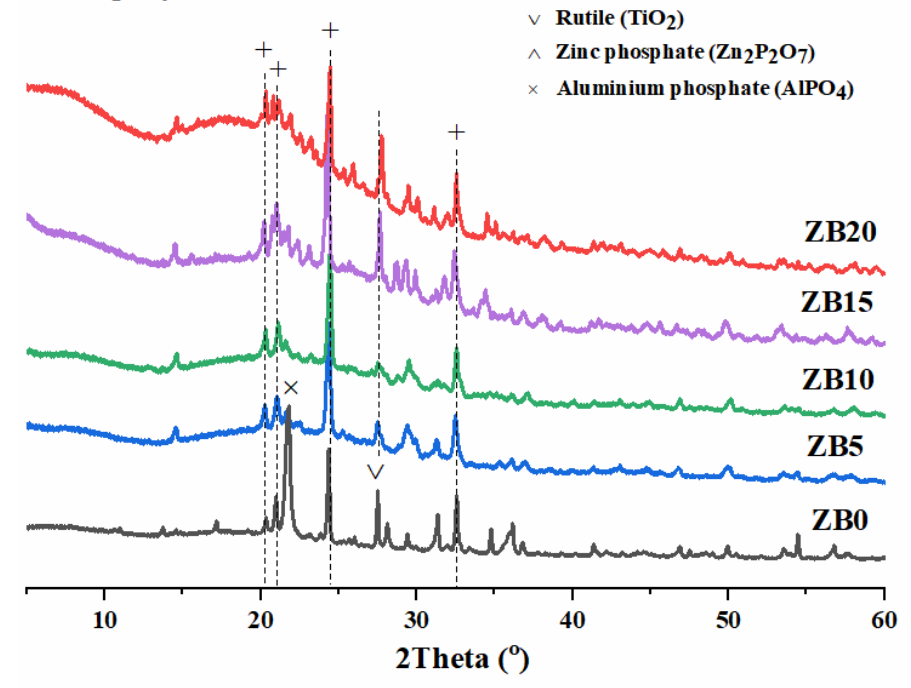

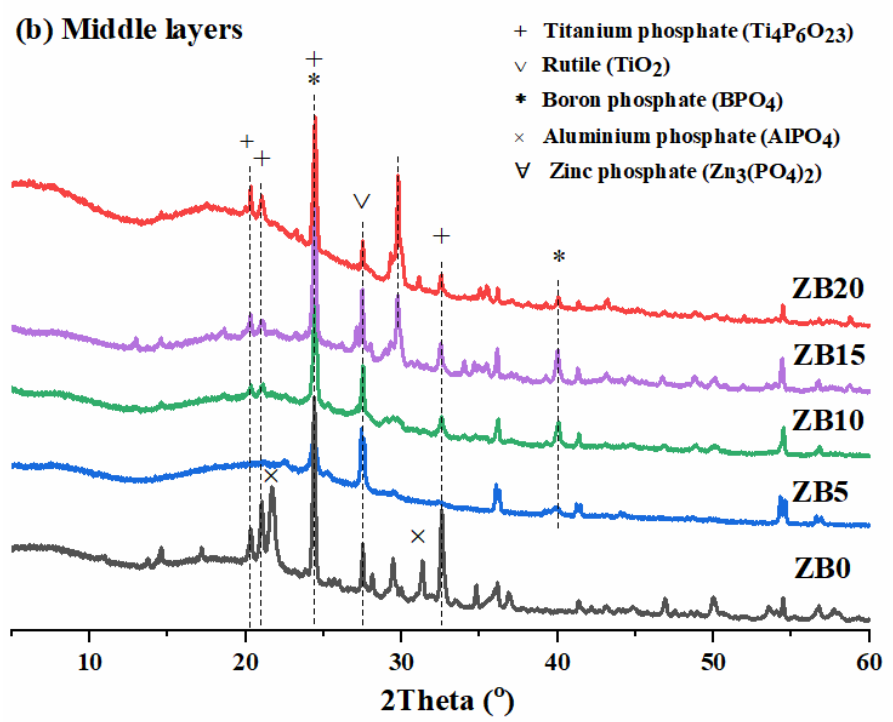

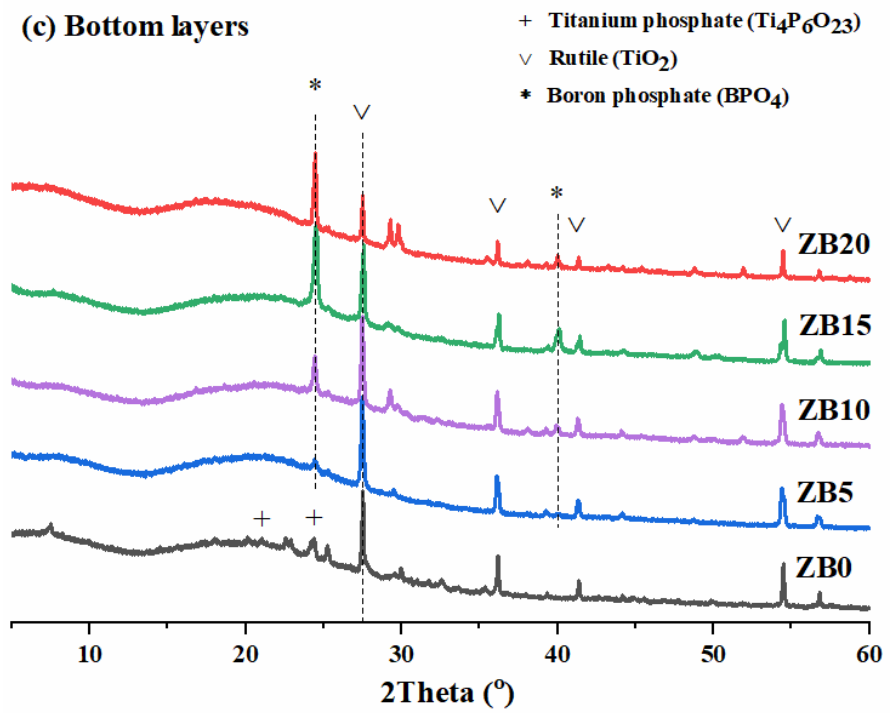

Figure 8 XRD patterns of the three layers (see Figure 7) of the intumescent chars ZB0 - ZB20. 
The difference of the compositions between the formulations is revealed by comparing the patterns of the same layer. With the introduction of zinc borate, the main crystal phase of the char is changed from $\mathrm{Ti}_{4} \mathrm{P}_{6} \mathrm{O}_{23}$ to $\mathrm{Ti}_{4} \mathrm{P}_{6} \mathrm{O}_{23}$ and $\mathrm{BPO}_{4}$, especially in the middle layers. The intensity of the characteristic peak of $\mathrm{BPO}_{4}\left(2 \theta=40.0^{\circ}\right)$ and $\mathrm{Ti}_{4} \mathrm{P}_{6} \mathrm{O}_{23}\left(2 \theta=32.4^{\circ}\right)$ are enhanced with increasing contents of zinc borate. It suggests that high levels of zinc borate cannot only facilitate the formation of $\mathrm{BPO}_{4}$, but may also enhance the conversion of $\mathrm{TiO}_{2}$ into $\mathrm{Ti}_{4} \mathrm{P}_{6} \mathrm{O}_{23}$. This may be explained by interactions between $\mathrm{TiO}_{2}$ and $\mathrm{ZnO}$, the latter being a product of zinc borate. Upon heating, the $\mathrm{TiO}_{2}-\mathrm{ZnO}$ system can form non-stable compounds like $\mathrm{Zn}_{2} \mathrm{Ti}_{3} \mathrm{O}_{8}$ [36]. These compounds may serve as intermediates in the conversion of $\mathrm{TiO}_{2}$ to $\mathrm{Ti}_{4} \mathrm{P}_{6} \mathrm{O}_{23}$, providing a reaction path with a lower energy barrier. The inorganic layer (e.g. $\mathrm{BPO}_{4}$ and $\mathrm{Ti}_{4} \mathrm{P}_{6} \mathrm{O}_{23}$ ) of chars contributes to improved mechanical properties and better resistance to thermal radiation and oxidation $[8,32]$.

Considering the fact that $\mathrm{BPO}_{4}$ is dominant in the bottom layers of the char, it can be speculated that the reaction between zinc borate and polyphosphoric acid may start at a lower temperature, at least lower than the formation temperature of $\mathrm{Ti}_{4} \mathrm{P}_{6} \mathrm{O}_{23}$, which is rich in the top layers. Bourbigot et al. [37] reported that zinc borate reacts with the degradation products of APP between 300 and 415 ${ }^{\circ} \mathrm{C}$, which falls into the temperature range of the melting stage (expansion region) in Figure 6. With increased zinc borate contents, a larger fraction of liquid polyphosphoric acids is converted into crystalline $\mathrm{BPO}_{4}$. The increased yield of $\mathrm{BPO}_{4}$ gives a more solid-like char during the melting stage and may, therefore, contribute to a smaller drop in dynamic viscosity as seen in Figure 6.

The positive effect on the yield of the crystal phases $\mathrm{BPO}_{4}$ and $\mathrm{Ti}_{4} \mathrm{P}_{6} \mathrm{O}_{23}$ was reduced when the content of zinc borate was increased to $20 \mathrm{wt}$ \% (ZB20). Instead of forming more crystal phases, the evident broad peak between $2 \theta=13.0^{\circ}$ and $2 \theta=25.0^{\circ}$ in the patterns of $Z$ B20 (especially in its middle and top layers) indicates that the formulation ZB20 yielded a considerable amount of amorphous phases in the char. This inference agrees with the observation of an abundance of non-porous glasslike spheres on the surface of the ZB20 char, which was barely seen on the surface of the other chars, e.g. ZB15 (Figure 9). The composition of these amorphous phases is not clear yet, but they may be formed from phosphates such as $\mathrm{BPO}_{4}, \mathrm{Ti}_{4} \mathrm{P}_{6} \mathrm{O}_{23}$, and $\mathrm{Zn}_{3}\left(\mathrm{PO}_{4}\right)_{2}$. This is in agreement with results of Bourbigot et al. [37], who found a yield of amorphous $\mathrm{B}_{2} \mathrm{O}_{3}$ due to a reaction between $\mathrm{BPO}_{4}$ and $\mathrm{Zn}_{3}\left(\mathrm{PO}_{4}\right)_{2}$. In fact, they used this reaction to explain the disappearance of $\mathrm{BPO}_{4}$ during the high-temperature treatment $\left(800{ }^{\circ} \mathrm{C}\right.$ for $3 \mathrm{~h}$ in air) of APP and zinc borate. According to our $\mathrm{XRD}$ results, the disappearance of $\mathrm{BPO}_{4}$ is also found in the patterns of the top layers (hightemperature region of the char), which may therefore also be attributed to this reaction. 

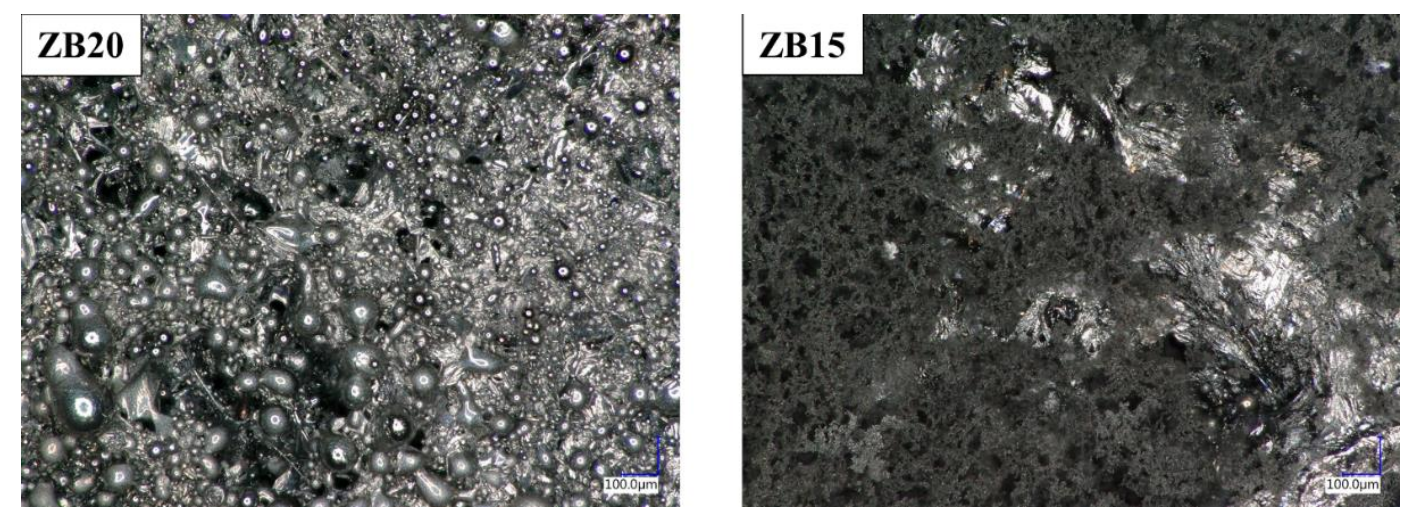

Figure 9 Digital microscopy images of the outer surface of the chars formed from ZB20 and ZB15 coatings.

\subsubsection{Thermal degradation of the formulations}

The thermal degradation of the formulations and the reactivity between ingredients were evaluated by thermogravimetric analyses coupled with gas detection using a Fourier transform infrared spectroscopy (TGA-FTIR). The mass loss and its first derivative with respect to time are plotted in Figure 10 as a function of temperature.

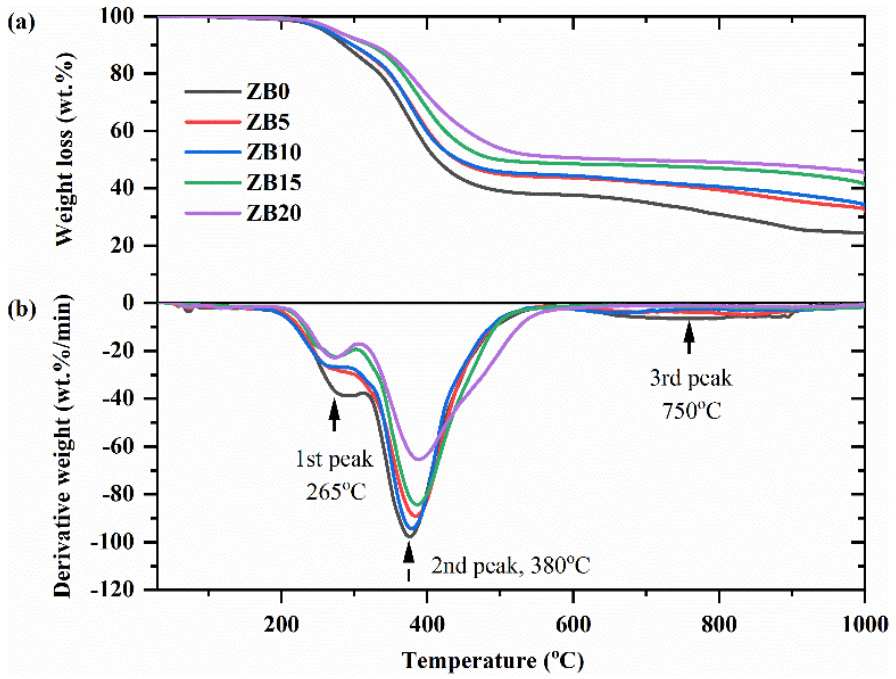

Figure 10 Mass loss curves (a) and the corresponding mass loss rate (b) for the intumescent coatings determined by TGA-FTIR.

The residual weights of the coatings increased from 24.59 (ZB0) to 45.58 wt.\% (ZB20) by raising the level of zinc borate in the formulation. Three peaks are identified in the curves of the mass loss rate. The first one started around $200{ }^{\circ} \mathrm{C}$ and can be assigned to the decomposition of the epoxy, yielding mainly $\mathrm{CO}_{2}, \mathrm{H}_{2} \mathrm{O}$, and aromatic species [38,39]. The second, with its maximum located at $380{ }^{\circ} \mathrm{C}$, is the most significant and complicated one, as the main reactions of intumescence are taking place in this range. According to the results of the thermogravimetric analyses on the 
individual ingredients (not shown here for brevity) and literature data [40,41], the decompositions of APP and MEL start around $300{ }^{\circ} \mathrm{C}$. The polyphosphoric acid derived from APP can thereby react with the epoxy binder (and its derivatives), which are rich in hydroxyl groups (-OH), via esterification. Zinc borate, $\mathrm{TiO}_{2}$, and $\mathrm{CaCO}_{3}$, at these temperatures, are available for reaction with the phosphoric acid as well $[37,42]$. The ammonia decomposed from APP and MEL is trapped and can diffuse to expand the material. The third peak in Figure 10b is quite typical for the gradual oxidation of the intumescent char. The appearance change of a char from black to light grey (e.g. ZB0) usually occurs at this stage depending on how prone the coating is to oxidation.

The increased residual weight from formulation $\mathrm{ZB} 0$ to $\mathrm{ZB} 20$ can be attributed to the interaction between zinc borate and other ingredients, which might retain more substances in the residual char by exhibiting a stabilization behavior on the degradation of the coating (e.g. decomposition of the epoxy binder or oxidation of the char). The stabilization behavior is clear in Figure 11 by comparing the actual residual weights and the theoretical residual weights of a formulation with zinc borate at 310,600 , and $1000{ }^{\circ} \mathrm{C}$. The temperatures selected, agree with the position of the ends of the peaks in Figure $10 \mathrm{~b}$.

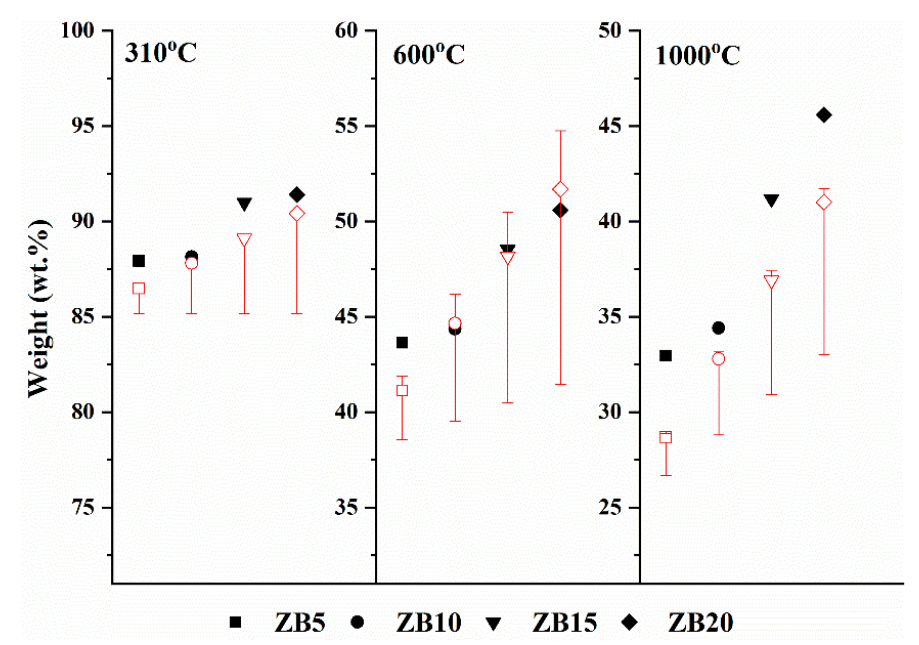

Figure 11 Comparison of actual (black solid points) and theoretical residual weights (red hollow points) of the coatings with zinc borate at 310,600 , and $1000{ }^{\circ} \mathrm{C}$.

Compared with the theoretical value, all the formulations with zinc borate show an increased residual weight at $310{ }^{\circ} \mathrm{C}$. The biggest improvement is found in the formulation $\mathrm{ZB} 15$, which corresponds to the most effective coating for stabilizing the epoxy in the early stage of thermal degradation. The stabilizing behavior becomes, however, less conspicuous at $600{ }^{\circ} \mathrm{C}$, except for the case of ZB5. At $1000{ }^{\circ} \mathrm{C}$, the notable difference appears between the actual and the theoretical residual weights of the formulations. Due to the reactions between 600 and $1000{ }^{\circ} \mathrm{C}$ being assigned to oxidation of the chars, the increased difference from 600 to $1000{ }^{\circ} \mathrm{C}$ may demonstrate the 
positive effect of zinc borate on the anti-oxidation of the chars. The anti-oxidation property is rooted in the chemical compositions of the intumescent chars. According to the results of X-ray diffraction (Section 3.1.3), the increased yield of $\mathrm{BPO}_{4}$ and $\mathrm{Ti}_{4} \mathrm{P}_{6} \mathrm{O}_{23}$, caused by formulating with more zinc borate in the coating, were found. These phosphates, converted by consuming (poly)phosphoric acids that can sublimate through dehydration to $\mathrm{P}_{4} \mathrm{O}_{10}$ higher than around $600{ }^{\circ} \mathrm{C}$, are thermally stable and can resist the high temperature of a hydrocarbon fire. Therefore, the increased yield of phosphates may contribute to the anti-oxidation of the chars by serving as the inorganic layers with the function of limiting oxygen diffusion inside the char [18]. Besides, more phosphate radicals retained by $\mathrm{BPO}_{4}$ and $\mathrm{Ti}_{4} \mathrm{P}_{6} \mathrm{O}_{23}$ also favor the increment of the final residual weights.

The gas evolution during the thermogravimetric analyses was monitored by the TGA-FTIR. The absorbance spectrum of the volatiles (in the form of a gas at $200{ }^{\circ} \mathrm{C}$ ) was collected continuously and the main characteristic peaks observed on the spectra corresponds to $\mathrm{NH}_{3}\left(800 \mathrm{~cm}^{-1}-1100 \mathrm{~cm}^{-1}\right), \mathrm{CO}_{2}$ $\left(2200 \mathrm{~cm}^{-1}-2400 \mathrm{~cm}^{-1}\right)$, and some aromatic species $\left(1100 \mathrm{~cm}^{-1}-1700 \mathrm{~cm}^{-1}, 2800 \mathrm{~cm}^{-1}-3200 \mathrm{~cm}^{-1}\right)$. The absorbance (the area of characteristic peak) of $\mathrm{NH}_{3}$ and $\mathrm{CO}_{2}$ for the formulations are illustrated in Figure $12 \mathrm{a}$ and $12 \mathrm{~b}$ as a function of temperature.
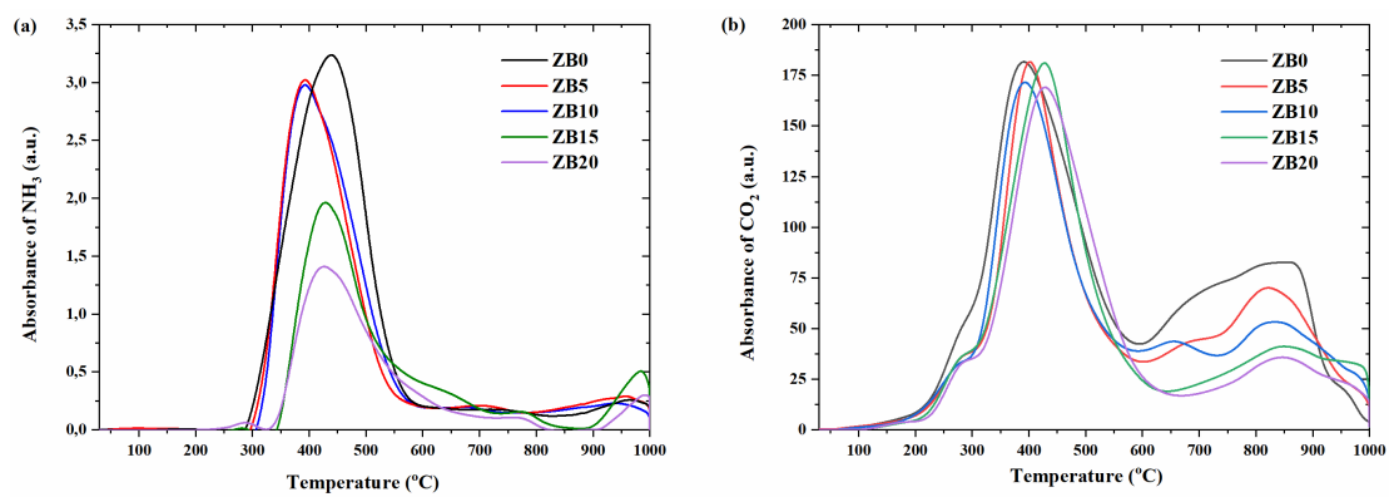

Figure 12 Evolution of $\mathrm{NH}_{3}$ (a) and $\mathrm{CO}_{2}$ (b) release for the intumescent coatings during TGA-FTIR measurements.

The $\mathrm{NH}_{3}$ absorbance appeared at around $300{ }^{\circ} \mathrm{C}$ for the formulations in Figure 12a. It coincides with the temperature at which APP and MEL initiate decomposition and releasing of $\mathrm{NH}_{3}$. The decreased $\mathrm{NH}_{3}$ absorbance is seen when increasing the level of zinc borate, especially from ZB10 to ZB15. It probably results from the high load of zinc borate, which constrained the decomposition of APP, MEL, or the amide group of the cured epoxy, as these are the sources of $\mathrm{NH}_{3}$ reported in the literature $[8,43]$. In Figure $12 \mathrm{~b}$, the absorbance of $\mathrm{CO}_{2}$ is observed at almost the same temperature as the decomposition of epoxy started in Figure 10. All formulations presented a similar evolution of $\mathrm{CO}_{2}$ until the temperature reached about $600{ }^{\circ} \mathrm{C}$. The $\mathrm{CO}_{2}$ absorbance after $600{ }^{\circ} \mathrm{C}$ dwindles 
significantly as a function of zinc borate content, which supports the statement regarding the effect of zinc borate on improving the anti-oxidation of the chars.

With respect to aromatic species, the characteristic peak area is too complex to be determined by the FTIR software. Therefore, the evolution of the aromatic species is merely presented in Figure 13 by the spectrum of a formulation that showed the strongest absorbance signal of the phenolic group.

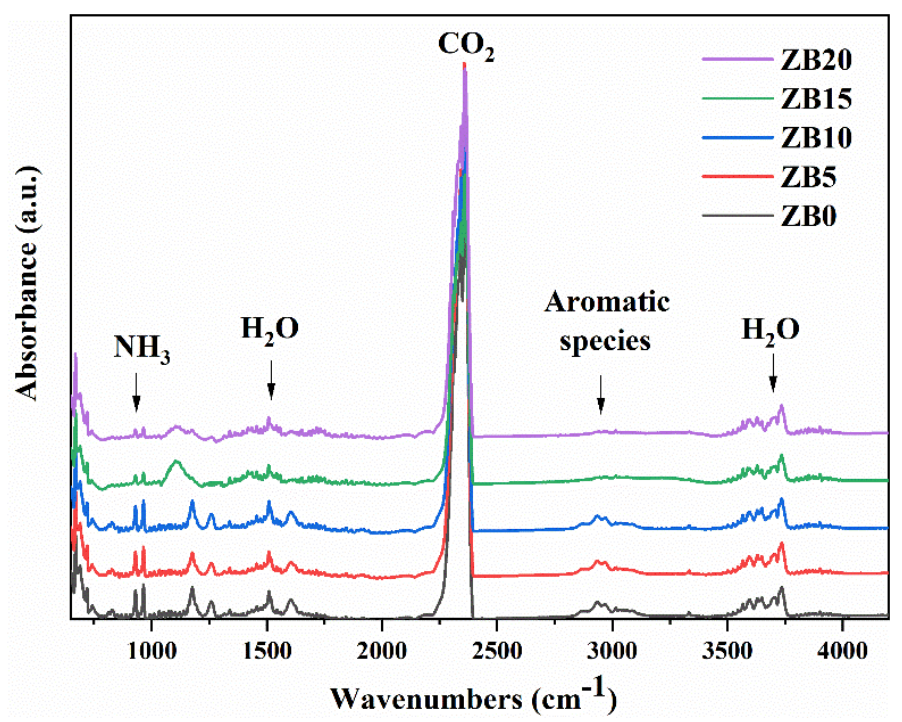

Figure 13 Spectra of the formulations when the strongest absorbance of aromatic species was identified in the TGAFTIR measurement. The corresponding temperatures of the spectra are: $390{ }^{\circ} \mathrm{C}(\mathrm{ZB} 0), 380{ }^{\circ} \mathrm{C}(\mathrm{ZB} 5), 380{ }^{\circ} \mathrm{C}(\mathrm{ZB} 10)$, $400{ }^{\circ} \mathrm{C}(\mathrm{ZB} 15)$, and $400{ }^{\circ} \mathrm{C}(\mathrm{ZB} 20)$.

The characteristic peaks of the aromatic species diminish with the increased content of zinc borate and nearly disappear when it comes to ZB15. According to the results in Figure 11 at $310^{\circ} \mathrm{C}$, zinc borate shows a stabilization behavior on the thermal degradation of the epoxy binder. With reduced polymer degradation, the release of the low-molecular-weight aromatic species (derived from the epoxy binder) is expected to decrease. The interaction between zinc borate and the epoxy binder is probably, as mentioned elsewhere, that boron compounds can minimize the polymer decomposition and the evolution of the volatiles by promoting crosslinking of the polymeric materials $[18,44]$. It is noted that this interaction might also support the reduced dynamic viscosity drop during the melting stage of the formulations and improve the anti-oxidation of the intumescent chars, as more crosslinked polymer materials usually bring increased dynamic viscosity and enhance the ability to resist oxidation [45].

\subsection{Clues to alternatives to zinc borate}

Overall, zinc borate influences almost all the relevant physical (expansion, viscosity) and chemical (char composition, thermal degradation) properties of the intumescent coatings. This complex effect 
gives improved fire-resistance performance when increasing the level of zinc borate in the formulation up to $15 \mathrm{wt} . \%$, even though the absolute difference between the critical times is small. Among these, the most prominent role of zinc borate is that it can significantly change the morphological structure of the intumescent char. The fluffy and soft char, formed with the zinc borate-free formulation, not only disfavors the heat shielding (as shown in Figure 2) but more importantly also cannot resist the turbulent flame of a hydrocarbon fire or even gravitational force. The risk of the latter is not evaluated with our furnace experiments, as the coatings were exposed horizontally with static-electrical heating. However, a partial or complete detachment of the intumescent char from the substrate is expected in an industrial hydrocarbon fire test due to the inferior structure, leading to loss of the fire-protection role of the char. Therefore, it is clear that the effect of zinc borate on improving the char structure is important for intumescent coatings exposed to a hydrocarbon fire scenario, even though the introduction of zinc borate limits the char expansion.

Nevertheless, the positive effects of zinc borate on making a uniform char structure should be the paramount factor taken into account when seeking an alternative to zinc borate. In other words, the alternative is expected to show at least the comparable behavior on improving the char structure. It would be better if the alternative can present less impact on char expansion. Instead of checking many formulations with time-consuming fire tests, the strong correlation between the char structure and the rheological properties suggests an easier way to predict the effect of an alternative chemical on the char structure by looking into the dynamic viscosity drop during the melting stage (expansion region) of an intumescent coating. According to the studies on the chemical composition of the chars and the thermal reactivity of the formulations, the effect of zinc borate on reducing the dynamic viscosity drop might relate to the increased yield of $\mathrm{BPO}_{4}$ and a stabilization behavior in the decomposition of the epoxy binder. The formation of $\mathrm{BPO}_{4}$, on the one hand, starts at the melting stage of the coatings and takes an active role in changing the dynamic viscosity drop of the incipient char. On the other hand, $\mathrm{BPO}_{4}$ is quite stable even at a temperature higher than $1200{ }^{\circ} \mathrm{C}$ [15], which can effectively retain phosphorous oxide and serve as the protection layer for antioxidation. With respect to the stabilization behavior of zinc borate in the decomposition of the epoxy binder, it was not fully investigated in this work how zinc borate affects polymer degradation. According to earlier work [18,44], most boron complexes are Lewis acids and can promote crosslinking reactions and minimize decomposition of polymeric materials.

\section{Conclusions}

Zinc borate has been investigated with respect to its effect on the performance of the hydrocarbon intumescent coatings. Furnace experiments, according to the UL1709 curve, were carried out to 
assess the fire-resistance performance of the coatings with different levels of zinc borate. The use of $15 \mathrm{wt} \%$ zinc borate in the coating was the most efficient formulation, with the longest critical time for both 400 and $550{ }^{\circ} \mathrm{C}$. The chars produced from the furnace experiments show that zinc borate can lower the cell (void) size and promote a uniform char structure even though a high char expansion is sacrificed. The effect of zinc borate on the char structure and the char expansion can be explained by the dynamic viscosity change during the intumescent process. Increasing the zinc borate content, significantly increases the dynamic viscosity of the viscoelastic material that forms during the expansion. A moderate dynamic viscosity can accommodate the pressure from the evolving gas and create a more homogeneous and firm char. However, excessively high viscosities may lead to a rigid char with defects such as cracks and delamination. X-ray diffraction studies of char layers demonstrated increased yields of phosphates (especially $\mathrm{BPO}_{4}$ ) as the level of zinc borate rises in the formulation. The thermogravimetric analyses and the gas evolution during the degradation of the coatings suggest that zinc borate can improve the residual weight of the char by stabilizing the epoxy binder and improving the anti-oxidation property. The effect of zinc borate on the yield of $\mathrm{BPO}_{4}$ and on reducing the thermal degradation of the coatings is related to the increased dynamic viscosity of the formulations during the melting stage (expansion region).

\section{Acknowledgments}

Financial support from the Hempel Foundation to CoaST (The Hempel Foundation Coatings Science and Technology Centre) and Hempel A/S is gratefully acknowledged.

\section{Declarations of interest}

None

\section{Data availability}

The raw and processed data required to reproduce these findings are available to download from [https://data.mendeley.com/datasets/s5r9cgbg32/draft?a=c17da54f-e99f-4a81-ae21-c1d9a5c71bac].

\section{Reference}

[1] I. Inerhunwa, Y. Chang Wang, M. Su, Reliability analysis of intumescent coating protected steel members under the standard fire condition, Fire Saf. J. 104 (2019) 43-56.

[2] J. Outinen, P. Mäkeläinen, Mechanical properties of structural steel at elevated temperatures and after cooling down, Fire Mater. 28 (2004) 237-251.

[3] European committee for standardizaion, EN 1993-1-2: Eurocode 3: Design of steel structures - Part 1-2: General rules - Structural fire design, Br. Stand. Inst. 2 (2005). 
[4] W.E. Luecke, J.L. Gross, J.D. Mccolskey, High-temperature tensile constitutive models for structural steel in fire, Natl. Inst. Stand. Technol. Tech. Note 1714. (2011).

[5] M. Jimenez, S. Duquesne, S. Bourbigot, High-throughput fire testing for intumescent coatings, Ind. Eng. Chem. Res. 45 (2006) 7475-7481.

[6] M.C. Yew, N.H. Ramli Sulong, M.K. Yew, M.A. Amalina, M.R. Johan, Influences of flameretardant fillers on fire protection and mechanical properties of intumescent coatings, Prog. Org. Coatings. 78 (2015) 59-66.

[7] J. Yuan, Intumescent coating performance on steel structures under realistic fire conditions, University of Manchester, 2009.

[8] J. Alongi, Z. Han, S. Bourbigot, Intumescence: Tradition versus novelty. A comprehensive review, Prog. Polym. Sci. 51 (2015) 28-73.

[9] R.G. Puri, A.S. Khanna, Intumescent coatings: A review on recent progress, J. Coatings Technol. Res. 14 (2017) 1-20.

[10] T. Mariappan, Recent developments of intumescent fire protection coatings for structural steel: A review, J. Fire Sci. 34 (2016) 120-163.

[11] K.P. Nørgaard, K. Dam-Johansen, S. Kiil, P. Català, Engineering model for intumescent coating behavior in a pilot-scale gas-fired furnace, AIChE J. 62 (2016) 3947-3962.

[12] Q.F. Gillani, F. Ahmad, M.I. Abdul Mutalib, P.S.M. Megat-Yusoff, S. Ullah, P.J. Messet, M. Zia-ul-Mustafa, Thermal degradation and pyrolysis analysis of zinc borate reinforced intumescent fire retardant coatings, Prog. Org. Coatings. 123 (2018) 82-98.

[13] Scientific Committee on Consumer Safety (SCCS), Opinion On Boron compounds, (2010).

[14] S. Ullah, F. Ahmad, A.M. Shariff, M.A. Bustam, Synergistic effects of kaolin clay on intumescent fire retardant coating composition for fire protection of structural steel substrate, Polym. Degrad. Stab. 110 (2014) 91-103.

[15] S. Ullah, F. Ahmad, P.S.M.M. Yusoff, Effect of boric acid and melamine on the intumescent fire-retardant coating composition for the fire protection of structural steel substrates, J. Appl. Polym. Sci. 128 (2013) 2983-2993.

[16] S. Ullah, F. Ahmad, Effects of zirconium silicate reinforcement on expandable graphite based intumescent fire retardant coating, Polym. Degrad. Stab. 103 (2014) 49-62.

[17] S. Ullah, F. Ahmad, P.S.M. Megat-Yuso, Effect of boric acid with kaolin clay on thermal degradation of intumescent fire retardant coating, J. Appl. Sci. 11 (2011) 3645-3649.

[18] S. Ullah, F. Ahmad, A.M. Shariff, M.A. Bustam, G. Gonfa, Q.F. Gillani, Effects of ammonium polyphosphate and boric acid on the thermal degradation of an intumescent fire retardant coating, Prog. Org. Coatings. 109 (2017) 70-82.

[19] C. Feng, Y. Zhang, D. Liang, S. Liu, Z. Chi, J. Xu, Influence of zinc borate on the flame retardancy and thermal stability of intumescent flame retardant polypropylene composites, $\mathrm{J}$. Anal. Appl. Pyrolysis. 115 (2015) 224-232.

[20] M.C. Yew, N.H. Ramli Sulong, M.K. Yew, M.A. Amalina, M.R. Johan, Eggshells: A novel bio-filler for intumescent flame-retardant coatings, Prog. Org. Coatings. 81 (2015) 116-124.

[21] J. Wang, G. Wang, Influences of montmorillonite on fire protection, water and corrosion resistance of waterborne intumescent fire retardant coating for steel structure, Surf. Coatings Technol. 239 (2014) 177-184. 
[22] B. Gardelle, S. Duquesne, P. Vandereecken, S. Bellayer, S. Bourbigot, Resistance to fire of intumescent silicone based coating: The role of organoclay, Prog. Org. Coatings. 76 (2013) $1633-1641$.

[23] B. Gardelle, S. Duquesne, P. Vandereecken, S. Bourbigot, Characterization of the carbonization process of expandable graphite/silicone formulations in a simulated fire, Polym. Degrad. Stab. 98 (2013) 1052-1063.

[24] M.K. Yew, M.C. Yew, L.H. Saw, J.H. Beh, Y.J. King, R. Durairaj, Effects of flame retardant nano bio-based filler on fire behaviors of intumescent coating, Mater. Sci. Forum. 947 (2019) $142-147$.

[25] M. Yasir, F. Ahmad, P.S.M. Megat-Yusoff, S. Ullah, M. Jimenez, Quantifying the effects of basalt fibers on thermal degradation and fire performance of epoxy-based intumescent coating for fire protection of steel substrate, Prog. Org. Coatings. 132 (2019) 148-158.

[26] A. Lucherini, N. Abusamha, J. Segall-Brown, C. Maluk, Experimental study on the onset of swelling for thin intumescent coatings, J. Phys. Conf. Ser. 1107 (2018) 32017.

[27] A. Lucherini, C. Maluk, Assessing the onset of swelling for thin intumescent coatings under a range of heating conditions, Fire Saf. J. 106 (2019) 1-12.

[28] G. Wang, J. Yang, Influences of molecular weight of epoxy binder on fire protection of waterborne intumescent fire resistive coating, Surf. Coatings Technol. 206 (2012) 2146-2151.

[29] Y. Dong, G. Wang, J. Yang, Influences of silicone emulsion on fire protection of waterborne intumescent fire-resistive coating, J. Coatings Technol. Res. 11 (2014) 231-237.

[30] G. Wang, J. Yang, Influences of glass flakes on fire protection and water resistance of waterborne intumescent fire resistive coating for steel structure, Prog. Org. Coatings. 70 (2011) 150-156.

[31] S. Murat Unlu, U. Tayfun, B. Yildirim, M. Dogan, Effect of boron compounds on fire protection properties of epoxy based intumescent coating, Fire Mater. 41 (2017) 17-28.

[32] H. Li, Z. Hu, S. Zhang, X. Gu, H. Wang, P. Jiang, Q. Zhao, Effects of titanium dioxide on the flammability and char formation of water-based coatings containing intumescent flame retardants, Prog. Org. Coatings. 78 (2015) 318-324.

[33] G. Canosa, P. V Alfieri, C.A. Giudice, Hybrid intumescent coatings for wood protection against fire action, Ind. Eng. Chem. Res. 50 (2011) 11897-11905.

[34] M. Jimenez, S. Duquesne, S. Bourbigot, Multiscale experimental approach for developing high-performance intumescent coatings, Ind. Eng. Chem. Res. 45 (2006) 4500-4508.

[35] P. Anna, G. Marosi, S. Bourbigot, M. Le Bras, R. Delobel, Intumescent flame retardant systems of modified rheology, Polym. Degrad. Stab. 77 (2002) 243-247.

[36] Y.-S. Chang, Y.-H. Chang, I.-G. Chen, G.-J. Chen, Y.-L. Chai, T.-H. Fang, S. Wu, Synthesis, formation and characterization of $\mathrm{ZnTiO}_{3}$ ceramics, Ceram. Int. 30 (2004) 2183-2189.

[37] F. Samyn, S. Bourbigot, S. Duquesne, R. Delobel, Effect of zinc borate on the thermal degradation of ammonium polyphosphate, Thermochim. Acta. 456 (2007) 134-144.

[38] X. Zhang, Y. Wu, X. Chen, H. Wen, S. Xiao, Theoretical study on decomposition mechanism of insulating epoxy resin cured by anhydride, Polymers 9 (2017) 341.

[39] N. Grassie, M.I. Guy, Degradation of epoxy polymers: Part 1-Products of thermal degradation of bisphenol-a diglycidyl ether, Polym. Degrad. Stab. 12 (1985) 65-91. 
[40] L. Costa, G. Camino, Thermal behaviour of melamine, J. Therm. Anal. 34 (1988) 423-429.

[41] B. V. Lotsch, W. Schnick, New light on an old story: Formation of melam during thermal condensation of melamine, Chem. - A Eur. J. 13 (2007) 4956-4968.

[42] K.P. Nørgaard, K. Dam-Johansen, P. Català, S. Kiil, Laboratory and gas-fired furnace performance tests of epoxy primers for intumescent coatings, Prog. Org. Coatings. 77 (2014) $1577-1584$.

[43] N. Grassie, M.I. Guy, N.H. Tennent, Degradation of epoxy polymers: Part 4-Thermal degradation of bisphenol-A diglycidyl ether cured with ethylene diamine, Polym. Degrad. Stab. 14 (1986) 125-137.

[44] I. Touval, Flame retardants, antimony and other inorganic agents, in: Kirk-Othmer Encycl. Chem. Technol., John Wiley \& Sons, Inc., Hoboken, NJ, USA, 2000.

[45] G. Wang, J. Yang, Influences of binder on fire protection and anticorrosion properties of intumescent fire resistive coating for steel structure, Surf. Coatings Technol. 204 (2010) 1186-1192. 